\title{
ISSN: 2641-1725
}

\section{Emergent Surgical Treatment Results of
Inflammatory Bowel Disease and Review of the \\ Emergent Surgical Treatment Results of
Inflammatory Bowel Disease and Review of the Literature}

\author{
Ceren Canbey Goret ${ }^{1 *}$, Nuri Emrah Goret ${ }^{2}$, Omer Faruk Ozkan ${ }^{3}$ and Guray Kilic ${ }^{4}$ \\ ${ }^{1}$ Department of Surgical Pathology, Health Sciences University, Sancaktepe Research and Education Hospital, Turkey \\ ${ }^{2}$ Department of General Surgery, Health Sciences University, Kartal Dr Lutfi Kirdar Research and Education Hospital, Turkey \\ ${ }^{3}$ Department of General Surgery, Health Sciences University, Umraniye Research and Education Hospital, Turkey \\ ${ }^{4}$ Department of Surgical Pathology, Private Ekin Pathology, Turkey
}

Received: 畊 August 16, 2018; Published: 畊 August 20, 2018

*Corresponding author: Ceren Canbey Goret, Department of Surgical Pathology, Health Sciences University, Sancaktepe Research and Education Hospital, Turkey

\begin{abstract}
Objective: Inflammatory bowel diseases (IBD) are a group of chronic gastrointestinal system diseases of which the etiology is unknown, and where environmental and genetic factors are influential. Among IBD cases, it has been reported that approximately $1 / 5$ of ulcerative colitis (UC) patients and 4/5 of patients with Crohn's disease (CD) require surgical intervention. In this study, we retrospectively investigated and presented 14 cases diagnosed as IBD and urgently operated, which are rarely reported in the literature.
\end{abstract}

Material and Method: We retrospectively evaluated who underwent bowel surgery for IBD. A total of 14 who underwent surgical resection of bowel with colectomy or/and segmental small bowel resection due to IBD lesions. Data were collected form Istanbul Ekin Private Pathology Laboratory and Çanakkale State Hospital were enrolled the study.

Results: Of the 14 cases that were urgently operated, four (28.6\%) were female, ten $(71.4 \%)$ were male, and the mean age was 45.2. One of the cases (7.1\%) was operated due to fistula, three $(21.5 \%)$ due to perforation and ten $(71.4 \%)$ due to obstruction. When the histopathological diagnosis of the cases was examined, it was seen that one case (7.1\%) was CD+adenocarcinoma, one case (7.1\%) was itestinal tuberculosis (tbc), and twelve cases (85.8\%) were CD.

Conclusion: Based on clinical and histopathological diagnosis, treatment in IBD cases should be regulated according to the localization and severity of the disease and the presence of complications. Surgical treatment should be preferred in IBD cases with inflammation despite medical treatments if remission cannot be achieved, complications such as obstruction/fistula occur, or neoplastic lesions are present.

Keywords: Inflammatory Bowel Disease; Crohn Disease; Tuberculosis Colitis; Adenocarcinoma with Crohn Disease; Urgent Surgery For IBD

\section{Introduction}

Inflammatory bowel diseases (IBD) represent a group of chronic gastrointestinal system disorders with an unknown aetiology in which environmental and genetic factors are involved [1]. Amongst patients with IBD, it was reported that approximately one-fifth of patients with ulcerative colitis (UC) and four-fifth of patients with

Crohn's disease (CD) require surgical intervention. Surgery can be preferred in cases such as unresponsiveness to immunomodulatory drugs, poor compliance of patients, the presence of multifocal dysplasia, obstruction, stricture and megacolon [2]. In patients with IBD, surgery can be elective or emergency, depending on the condition of the patient [3]. Subtotal colectomy plus ileostomy is 
reportedly the fold standard method in cases requiring emergency surgery [4]. The aim of the present study was to retrospectively review and present 14 patients with IBD who underwent emergency surgery.

\section{Materials and Methods}

Patients who underwent emergency surgery were retrospectively evaluated. The study parameters were collected from the patients' medical records, and a form was created for all patients. All data were recorded on the forms of each patient. Patients with missing data were excluded from the study. The study was conducted in accordance with the Helsinki declaration. A total of 14 IBH patients who underwent emergency surgery involving colectomy and/or segmental small bowel resection were included in the study. The data were collected from Ekin Özel Patoloji Laboratories between January 2010 and January 2016 and from Çanakkale State Hospital between January 2017 and January 2018. The data were analysed using Windows and Microsoft Excel 2016.

\section{Results}

Table 1: Distribution of all cases according to histopathologic diagnosis, indication for surgery and procedure.

\begin{tabular}{|c|c|c|c|}
\hline Surgical Procedure & $\begin{array}{c}\text { Number } \\
\text { of Cases } \\
n=14\end{array}$ & $\begin{array}{l}\text { Histopathologic } \\
\text { Diagnosis }\end{array}$ & $\begin{array}{l}\text { Surgical } \\
\text { Indication }\end{array}$ \\
\hline $\begin{array}{l}\text { Segmental resection } \\
\text { of jejunum }\end{array}$ & $\begin{array}{c}n=1 \\
(7.1 \%)\end{array}$ & $\mathrm{CD}$ & Perforation \\
\hline Left hemicolectomy & $\begin{array}{c}\mathrm{n}=1 \\
(7.1 \%)\end{array}$ & $\mathrm{CD}$ & Obstruction \\
\hline $\begin{array}{l}\text { Total colectomy + } \\
\text { ileotransversostomy }\end{array}$ & $\begin{array}{c}n=1 \\
(7.1 \%)\end{array}$ & Tbc colitis & Obstruction \\
\hline $\begin{array}{l}\text { Right } \\
\text { hemicolectomy + } \\
\text { ileotransversostomy }\end{array}$ & $\begin{array}{c}n=5 \\
(35.8 \%)\end{array}$ & $\begin{array}{c}\mathrm{CD}+ \\
\text { Adenocarcinoma } \\
(\mathrm{n}=1) \\
\mathrm{CD}(\mathrm{n}=4)\end{array}$ & $\begin{array}{l}\text { Obstruction (n } \\
\quad=4) \\
\text { Fistula }(\mathrm{n}=1)\end{array}$ \\
\hline $\begin{array}{c}\text { Segmental resection } \\
\text { of ileum }\end{array}$ & $\begin{array}{c}n=6 \\
(42.9 \%)\end{array}$ & $\mathrm{CD}$ & $\begin{array}{l}\text { Perforation (n } \\
\quad=2 \text { ) } \\
\text { Obstruction ( } \mathrm{n} \\
\quad=4)\end{array}$ \\
\hline
\end{tabular}

* CD: Crohn's Disease

** Tbc: Tuberculosis

Of a total of 14 patients who underwent emergency surgery, 4 (28.6\%) were female, $10(71.4 \%)$ were male, and the mean age was 45.2 (between 23 and 84 years). One patient underwent segmental resection of jejunum, 1 patient underwent left hemicolectomy, 1 patient underwent total colectomy + ileotransversostomy, 5 patients underwent right hemicolectomy + ileotransversostomy, and 6 patients underwent segmental resection of ileum. One (7.1\%) of the patients was operated due to fistula, 3 (21.5\%) patients due to perforation and 10 (71.4\%) patients' due obstruction. The histopathologic examination of the cases revealed that 1 (7.1\%) patient had CD + adenocarcinoma, 1 (7.1\%) patient had tuberculosis (Tbc) colitis, and $12(85.8 \%)$ patients had CD. The patient with adenocarcinoma $+\mathrm{CD}$ was a 23-year-old male who underwent right hemicolectomy + ileotransversostomy, whereas the patient with Tbc colitis was a 29-year-old male who underwent total colectomy + ileotransversostomy (Table 1).

\section{Discussion}

The preferred approach to therapy in patients with IBD that are unresponsive to medical therapy within 5-7 days and exhibiting severe exacerbations is surgery. It was reported that subtotal colectomy + ileostomy is the most commonly preferred procedure in patients with IBD requiring emergency surgery [4,5]. The most commonly preferred surgical procedures in our patients were segmental resection of ileum that was performed in 6 patients, and right hemicolectomy + ileotransversostomy that was performed in 5 patients (Figures $1 \& 2$ ). In a study by Hyman et al. reporting on 101 patients with IBD, they reported that they performed subtotal colectomy in all the patients. Of these patients, 22 underwent elective surgery and the others underwent emergency surgery [4]. In our study, all our patients were operated in an emergency setting because of obstruction, fistula and perforation associated with narrowing of the intestinal lumen (Figure 3). In the analysis of histopathologic diagnoses of the patients that underwent emergency surgery in the literature, ulcerative colitis (UC) and CD were among the most commonly reported diagnoses [6,7]. In our study, CD was the most common diagnosis among our patients with IBD. There were no cases of UC among our patients with IBH that underwent emergency surgery. We think that this was due to limited number of our cases.
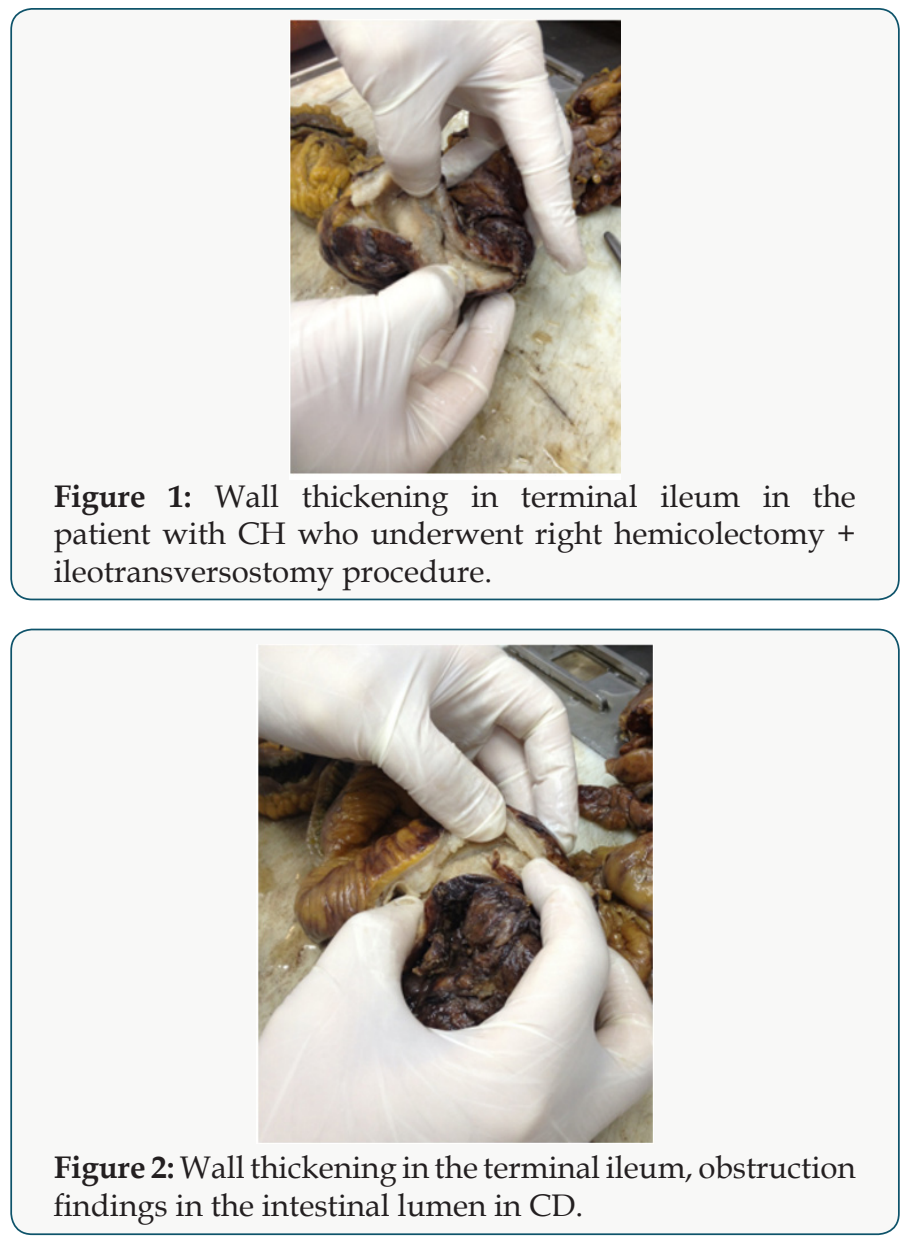


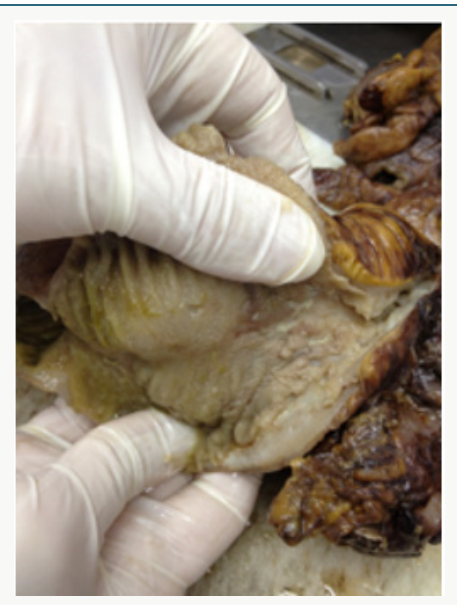

Figure 3: Discrete ulcers and areas of fissuring in terminal ileum in CD.

In one of our cases, CD was accompanied by adenocarcinoma in the right colon. It is known that the risk of intestinal carcinoma increases in both patients with Crohn's disease and UC. It is reported that the mechanism of carcinogenesis has not been fully understood, although carcinogenesis is thought to be secondary to chronic inflammation and is described more clearly in UC compared to CD. In UC, hypermethylation of tumour suppressors and DNA mismatch repair genes and p53 mutation mechanisms have been implicated [8,9]. As from the initial diagnosis, approximately $8 \%$ of cases develop colon carcinoma in 20 years and $18 \%$ in 30 years [10]. Our patient who was diagnosed with CD + adenocarcinoma was at the age of 23 , and we do not know when he received his first diagnosis. Likewise, one of our patients had Tbc colitis and underwent total colectomy due to obstruction. As is known, Tbc most commonly affects the lungs and there are reports indicating an increase in the rate of extrapulmonary Tbc [11]. In patients with intestinal Tbc, histopathological appearance can mimic IBD particularly $\mathrm{CD}$, and sometimes it produces a mass lesion that leads to confusion with malignancy [12].

The expected findings on histopathological examination include often classified granulomas surrounding the ulcers and particularly located in the submucosa showing tendency to coalesce in intestinal tuberculosis, and discrete ulcers, deep fissuring ulcers and noncaseified granulomas in CD. Although more commonly occurring in patients with UC, sometimes regeneration polyps can be seen around the ulcer sites macroscopically in patients with CD (Figures $4 \& 5$ ) [12]. In conclusion, the treatment must be tailored according to the localisation, severity and complications of disease in patients diagnosed with IBD based on clinical and histopathological findings. Depending on the localization of the disease, drugs targeting certain regions of the gastrointestinal tract may be used, or systemic corticosteroids and immunomodulatory drugs can be preferred. Surgical therapy must be preferred if the therapies fail to achieve remission or if the patients develop complications such as obstruction/fistula, remain refractory to therapy or in the presence of neoplastic lesions in patients with IBD exhibiting disease exacerbation.

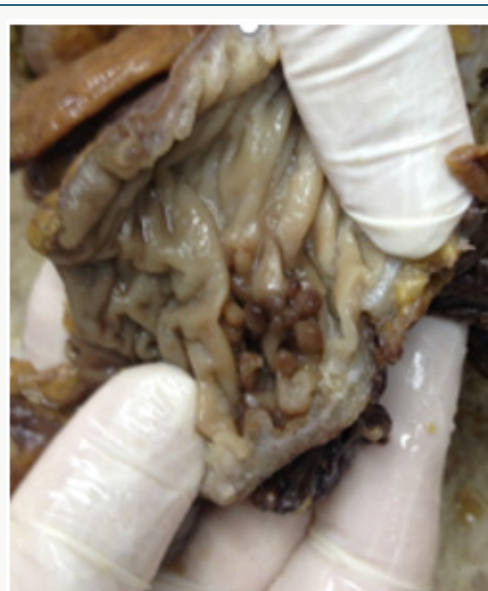

Figure 4: Regeneration polyps with ulceration on the surface of the colon in the patient with $\mathrm{CH}$ who underwent right hemicolectomy + ileotransversostomy.

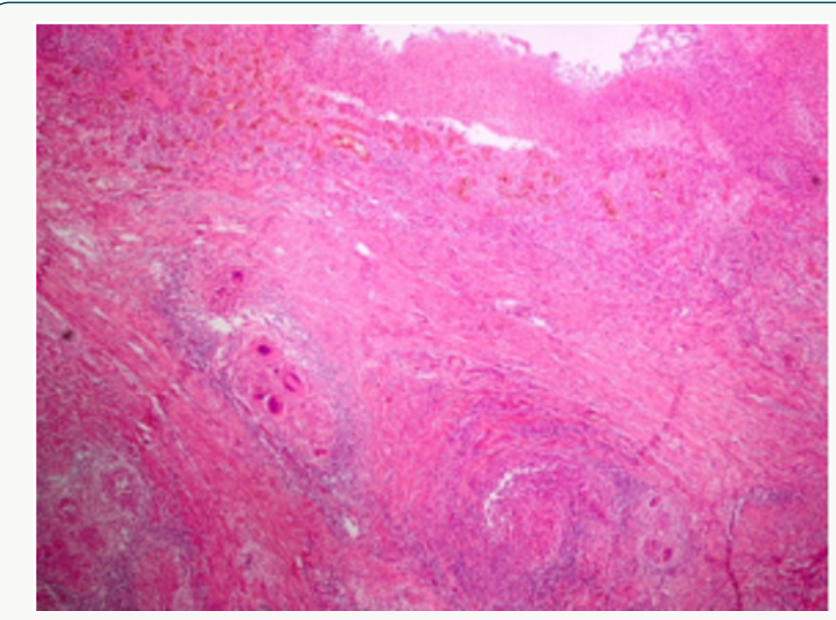

Figure 5: In the patient with intestinal tuberculosis, colonic mucosal ulcers, granulomas accompanied by caseating necrosis in the submucosa and Langhans giant cells (H\&E $\times 40)$.

\section{References}

1. A Agrusa, G Romano, G Lo Re, G Di Buono, F Vernuccio, et al. (2014) Hemoperitoneum following mild blunt abdominal trauma: first presentation of crohn's disease. Acta Medica Mediterranea 30: pp. 315.

2. Sica GS, Biancone L (2013) Surgery for inflammatory bowel disease in the era of laparoscopy. World J Gastroenterol 19(16): 2445-2448.

3. Hwang JM, Varma MG (2008) Surgery for inflammatory bowel disease. World J Gastroenterol. 14(17): 2678-2690.

4. Hyman NH, Cataldo P, Osler T (2005) Urgent subtotal colectomy for severe inflammatory bowel disease. Dis Colon Rectum 48(1): 70-73.

5. Penna C, Daude F, Parc R, Tiret E, Frileux P, et al. (1993) Previous subtotal colectomy with ileostomy and sigmoidostomy improves the morbidity and early functional results after ileal pouch-anal anastomosis in ulcerative colitis. Dis Colon Rectum 36(4): 343-348.

6. Hawley PR (1988) Emergency surgery for ulcerative colitis. World J Surg 12(2): 169-173.

7. Katz JA (2000) Medical and surgical management of severe colitis. Semin Gastrointest Dis 11(1): 18-32.

8. Mescoli C, Frego M, Rugge M (2011) Pathology of dysplasia and cancer in inflammatory bowel disease. Ann Ital Chir 82(1): 11-18. 
9. Pozza A, Scarpa M, Ruffolo C, Polese L, Erroi F, et al. (2011) Colonic carcinogenesis in IBD: molecular events. Ann Ital Chir 82(1): 19-28.

10. Munkholm P (2003) The incidence and prevalence of colorectal cancer in inflammatory bowel disease. Aliment Pharmacol Ther 18 (suppl 2): $1-5$.
11. Ozkan OF, Ozkul F, Caymaz I, Güner A, Kant A, et al. (2013) A case of intestinal obstruction due to ileocecal tuberculosis. Turk J Gastroenterol 24(2): 190-192.

12. Ozkan OF, Goret CC, Goret NE, Yuksekdag S, Unal E (2017) A Diagnostic and Therapeutic Dilemma: Intestinal Tuberculosis. Clin Infect Dis 1(1): pp. 101.

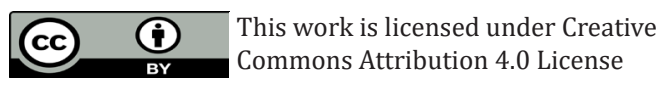

To Submit Your Article Click Here:

Submit Article

\begin{tabular}{l}
$\begin{array}{c}\text { Lupine Online Journal of } \\
\text { Medical Sciences }\end{array}$ \\
Assets of Publishing with us \\
- Global archiving of articles \\
- Immediate, unrestricted online access \\
- Rigorous Peer Review Process \\
- Authors Retain Copyrights \\
\hline Lupine Online
\end{tabular}

